\title{
Austrian Pinot blanc wines: Typicity, wine styles and the influence of different oenological decisions on the volatile profile of wines
}

\author{
C. Philipp, S. Sari, P. Eder, E. Patzl-Fischerleitner, and R. Eder \\ Höhere Bundeslehranstalt und Bundesamt für Wein- und Obstbau, Wienerstraße 74, 3400 Klosterneuburg, Austria
}

\begin{abstract}
Pinot blanc is found in all wine regions of Austria. However, it plays an economically subordinate role compared to the most important white grape variety, Grüner Veltliner. The concept of wine typicity and terroir is that the geographical origin and oenological practices, along with the grape variety, make an important contribution to the final expression of the finished wine. The purpose of this study was to discuss different styles of Austrian Pinot blanc wines and to discuss the various wine production decisions in terms of wine stylistics and aromatic profile. 131 commercial Austrian wine samples of the Pinot blanc variety of the 2015 to 2017 vintages were collected and the manufacturer's practices were determined by means of a questionnaire related to the wine styles. Using various GC-SIM-MS methods, more than 100 essential volatile substances were quantified. A trained panel, an expert panel and consumers evaluated the wines based on typicity and quality. 15 typical wines were then assessed on a sensory basis by means of predetermined aroma and wine styles. The four Austrian Pinot blanc wine styles previously discussed and presented by the same authors (citrus (1st style), green apple and green pear (2nd style), ripe yellow apple, quince, cooked pear, bread and honey notes (3rd style), as well as intensive oak notes (4th style)) were able to be partially reproduced by the trained panel. The following three wine styles could be better understood by the consumers: fresh fruity (style A), complex aroma with or without moderate wood (style B) and lots of wood aroma (style C). These styles (A-C) were able to withstand a sensory examination and a discriminant analysis by substance. An oenological guideline could help the producers to achieve the respective style. Austria's wine-growing area is probably too small and the importance of the Pinot blanc variety for the individual areas still too low to support the terroir concept for this grape variety.
\end{abstract}

\section{Introduction}

Pinot blanc is an old grape variety with some fans. Interestingly, it is experiencing an unexpected renaissance in Central Europe, especially in Germany, South Tyrol and Austria. In Austria, specialisations are to be found where Pinot blanc has now been approved as DAC (Districtus Austriae Controllatus). Accordingly, the regions around the Leithaberg and also the DAC areas in Styria increasingly deal with this old colour mutant of Pinot noir. In general, the distribution of the variety in Austria is relatively even. This means that Pinot blanc can be found everywhere, but it is not the most important grape variety anywhere and therefore plays an economically subordinate role in comparison with Grüner Veltliner [1]. However, with a total cultivated area of 1,992 ha hectares, Austria is the third largest Pinot Blanc-producing country in the world (14,834 hectares) [2].

The concept of wine typicity in terms of the terroir is of the opinion that the oenological practices, in addition to the grape variety and the geographical origin, make an important contribution to the final expression in the finished wine [3]. There are only a few scientific publications on the typicity of Pinot blanc wines and no papers that have dealt with the terroir for Pinot blanc production. Wines of this variety have always been considered rich in content and long-lasting. The typical aroma of Pinot blanc is described with pear, apple, quince, banana, apricot, caramel and citrus notes. For mature wines, bread flavours can be recognized. A longer bottle maturation allows the wine to gain in density and structure. The neutral aroma is considered to be less than trendy and the grape variety definitely does not have a youthful image [4]. Nevertheless, the wines tend to be in the upper quality and price range and are in great demand. In one study, 106 people ( 24 consumers, 34 winegrowers, 48 official wine tasters) in Austria were asked about the colour, flavour and taste characteristics of a typical Austrian Pinot blanc. The results showed that the terms ripe pomaceous fruit and nut flavours are most associated with Austrian Pinot blanc. For some wine categories, such as the reserve, wood and vanilla flavours play a crucial role [5]. Controversially, German Pinot blanc wines are often associated with the term pineapple [6]. Pinot blanc wines from South Tyrol are described with the flavour descriptors apple, pear, citrus notes, green notes, occasionally quince and exotic fruit, and in exceptional cases with spicy and nutty notes [7]. Furthermore, it was found that there is a positive correlation between wine quality, typicity and the perceived pear aroma of the Austrian Pinot blanc wines [8]. The perceived pear aroma is difficult to describe, as the studies [8-10] show. With the representation of sensoryanalytical typograms of the pear aroma, a simple model for the description of the pear aroma has been demonstrated 
and various influencing parameters on the composition of the typograms discussed [8-10].

Just as there are few papers on the typicity of Pinot blanc wines, there are even fewer scientific publications on the theme of Pinot blanc wine styles. Only [11] have discussed wine styles of typical Pinot blanc wines. The 15 most typical wines from a total sample number of 46 Pinot blanc of the 2016 vintage and Ausrian origin were evaluated by Napping®- method with 21 trained experts, 34 wine producers and 21 wine consumers. The results showed that the 15 wines were divided by the panel members into 4 wine styles. Pinot blanc with the descriptors ripe yellow fruit, bread, honey and brioche were grouped together. Furthermore, Pinot blanc clustered with green fruit flavours like green apple, green pear. As a third group Pinot blanc with citrus flavours were clustered in a group. The fourth Pinot blanc style described were wines with vanilla, oak and or nut flavours. A Kruskal-Wallis test revealed significant differences $(p<$ 0.05 ) between these different styles in perceived overall quality, perceived typicity, total alcohol, ethyl hexanoate, ethyl octanoate, methyl (E) -2,6-octadienoate, methyl and ethyl hexanoate content, ethyl decadienoate (isomers), ethyl dodecanoate, methyl vanillate, cis-whisky lactone, 1-butanol, (z) -linalool oxide and diacetyl [11].

The aim of this study was to test whether these four wine styles proposed by [11] are sensorially and analytically reproducible, or whether other to be defined wine styles are better suited for Austrian Pinot blanc wines. Furthermore, the oenological decisions made by the corresponding wine producers to achieve the wine styles were evaluated. As [12] proposed describing the typicity of wines both from the perspective of the producers and from the field of vision of the consumers, the typicity and style of the Austrian Pinot blanc wines should be considered from these poles in this paper.

\section{Material and methods}

\subsection{Samples}

131 different Pinot blanc wines from the years 2015 to 2017 were collected from a total of 64 wineries in Austria. The wines came from all relevant wine regions in the federal states of Burgenland, Vienna, Lower Austria and Styria. Depending on the wine production, the Pinot blancs were sourced from the producers after harvest from April to October and stored at $4{ }^{\circ} \mathrm{C}$ until analysis. The wines were described by the winemakers as typical of the variety and vintage. Metadata about the wines was then collected using an internet questionnaire (www.soscisurvey.de). A total of 13 questions were asked about sugar content, maceration time, press fractions, clarification variants, must finings, spontaneous fermentation, pure cultured yeast, fermentation tank, fermentation temperature, maturation choice, months of yeast contact, barrel storage and filtration.

\subsection{Sensory analyses}

To discuss different wine styles, sensory experiments were conducted with a consumer panel $(n=15)$ and a panel of people trained for the specific issues $(n=12)$. In addition, an expert panel $(n=6)$ was available.
The trained taster panel consisted of 12 people aged 24 to 46 years. Of these, 5 were female and 7 male, who were involved in wine production, analysis and evaluation in a variety of ways in everyday life and in their profession. The tasters were employees of the Federal College and Research Center of Viticulture and Pomology, students of agricultural science or oenology, employees of the University of Natural Resources and Life Sciences and winegrowers. The training of the panel was carried out in six units of 1.5 hours, so that the parameters, that were important for the assessment of the given wine styles, were imprinted. Possible Pinot blanc styles were further discussed in three units of 1.5 hours each.

The consumer panel consisted of 15 people who were to correspond to an average wine consumer and were not further defined. The expert panel consisted of persons qualified to participate in official wine tasting and have many years of experience in the sensory evaluation of wines. They said they had some expertise in evaluation of Pinot blanc too. The consumer panel and the expert panel were not given training.

The tasting sessions were held at the Federal College and Research Center of Viticulture and Pomology in Klosterneuburg in accordance with the guidelines of an ISO17025 accredited laboratory for quality wine testing. For the evaluation of the quality and typicity of the wines, the expert panel and the trained panel, but not the consumer panel, were interviewed together. The quality was evaluated in five batches (each with a maximum of 15 wines, anonymous and randomized) over two tasting sessions per year, according to a 20-point scheme, and the evaluation of the typicity of the wines using unstructured scales $(10 \mathrm{~cm})$ in duplicate. The tastings took place in the autumn of the year following the harvest.

In the course of this study, only 5 typical wines per year were supposed to be used for further sensory tests. The trained panel and the consumer had to rate 5 typical wines of the three vintages ( 15 wines in total) with regard to the type of wine. This happened in autumn of 2018. All wines were checked before tasting for any ageing defects and replaced in case of abnormalities by the next ranked wine. This happened in 3 cases. In the evaluation of the wine styles, the vintages were not evaluated separately due to their different maturity, but in three rounds, each with 10 wines (mixed from the three vintages, also possible double nominations, randomized and anonymous). Each taster had to evaluate 30 wines. The tasters were invited to taste one Pinot blanc after the other and then put them together in groups. They had to form at least 2 different groups but a maximum of 7 groups, whereby one wine could also be a group. Once the group formation had been completed, the trained panel had to label the groups created and describe them using the given terms. The following flavours were available: apricot, vineyard peach, green apple, overripe/ripe apple, pear, walnut, almond, hazelnut, grapefruit, lemon, pineapple, banana, mango, figs, apple compote, elderflower, wild flowers, fresh grass, asparagus, vanilla, cinnamon, pepper, coconut, burnt sugar, honey, oak, burnt wood, bacon, leather, sauerkraut, yoghurt, biscuit, honey, fresh bread and chocolate. The consumer panel only had to divide the groups into fruity and light, fruity and complex and complex with clear wood and vanilla notes. 


\subsection{Analytics}

For the determination of the basic parameters of the wines, FT-IR analyses according to OIV/OENO Resolution 390/2010 were carried out by means of a FOSS WineScan (FT 120 Reference Manual, Foss, Hamburg, Germany) [13].

Of the 15 selected wines, a total of 102 flavours of the aromatic group, esters, higher alcohols, carboxylic acids, carbonyl compounds, lactones, volatile phenols, free monoterpenes and free C13-norisoprenoids were analysed in duplicate using 6 different GC-SIM-MS methods. The content of decadienoic acid ethyl ester was determined according to [9] by means of HS-SPME-GC-SIM-MS. The quantification of the 14 relevant free monoterpenes was carried out according [14]. In addition, 32 esters were determined by Stable Isotope Dilution Assay Headspace Solid-Phase Microextraction Gas Chromatography Mass Spectroscopy (SIDA-HS-SPME-GC-MS). The method was developed by [15] especially for Pinot blanc wines. [16] was used to quantify the C13-norisoprenoids (1,1,6-trimethyl-1,2-dihydronaphthalene, and vitispirane). The determination of the volatile phenols and lactones was carried out according to [17]. The determination of the main quantitative flavourings such as relevant higher alcohols, relevant short and mid-chain carboxylic acids, carbonyl compounds and ester compounds were carried out by means of a partial SIDA-HS-SPME-GCMS method. An Agilent Technologies $6890 \mathrm{~N}$ Network GC system, an Agilent 5975 Inert Mass Selective Detector (both Agilent Technologies, Santa Clara USA) and a CTC Analytics autosampler (Zwingen, Switzerland) with a $65 \mu \mathrm{m}$, polydimethyl-siloxane/divinylbenzene (PDMS/DVB), fused silica/SS fibre core (SUPLECO, PA, USA) fibre were used. $1 \mathrm{~g}$ salt $(\mathrm{NaCl})$ was weighed into a $20 \mathrm{ml}$ vial and $2 \mathrm{ml}$ milli-Q water added. Then $1 \mathrm{ml}$ of the sample was pipetted to it. $50 \mu$ l each of the three internal standard solutions (acid standard: butanoic acidd7, hexanoic acid-d12, ester standard: ethylhexanaote-d5, ethyloctanoate-d5 and alcohol standard (butanol-d10 and hexanol-d13); in 2 butanone; nominal concentration 200 $\mu \mathrm{g} / \mathrm{l})$ were pipetted to it. The sample was pre-incubated in the autosampler unit (PAL) for one minute, then stirred at an incubation temperature of $30^{\circ} \mathrm{C}$ with a magnetic stirrer at $500 \mathrm{rpm}$ and extracted for 30 minutes. Subsequently, the fibre was injected into the gas chromatograph in "splitless mode" and the extracted sample was desorbed for 35 minutes at $245^{\circ} \mathrm{C}$. The $\mathrm{GC}$ instrument parameters were the same as in [18]. The samples were measured in single-ion mode (SIM). The evaluation was made using the relative ratio of the peak area of the sample to the peak area of the internal standard. The following standards were analysed and the $\mathrm{m} / \mathrm{z}$ ratios used for the quantification and the retention times are given in the bracket: 1-propanol (31, RT: $9.312 \mathrm{~min}$ ), isobutanol (42, RT: $11.487 \mathrm{~min})$, isoamyl alcohol (70, RT: $16.825 \mathrm{~min})$, 1-butanol (56, RT: $13.888 \mathrm{~min})$, (Z) -3-hexen-1-ol (82, RT: 24.817) diacetyl (43, RT: $6.932 \mathrm{~min})$, ethyl lactate (45, RT: $22.875 \mathrm{~min})$ ethyl acetate (61, RT: $4.687 \mathrm{~min})$, ethyl propanoate (57, RT: $6.364 \mathrm{~min})$, isovaleric acid (60, RT: $36.433 \mathrm{~min})$, 1-hexanol (69: RT: $23.495 \mathrm{~min})$, propionic acid (74, RT: $33.460 \mathrm{~min})$, butyric acid (60, RT: $35.203 \mathrm{~min}$ ), hexanoic acid (60, RT: $42.868 \mathrm{~min})$, octanoic acid (115, RT: $50.053 \mathrm{~min})$, isobutyric acid (43, RT:
Table 1. Determined typicity, quality and origin of the wines used for the wine style evaluation, ranked according to the typicity.

\begin{tabular}{|r|c|c|c|c|}
\hline No. & Vintage & Typicity & Quality & Wine region \\
\hline $\mathbf{1}$ & 2015 & 8.4 & 15.6 & Leithaberg \\
\hline $\mathbf{2}$ & 2016 & 7.9 & 17.4 & Kamptal \\
\hline $\mathbf{7}$ & 2016 & 7.7 & 16.0 & Klosterneuburg \\
\hline $\mathbf{1 1}$ & 2016 & 7.5 & 15,4 & Wagram \\
\hline $\mathbf{1 2}$ & 2017 & 7.5 & 15.6 & Kamptal \\
\hline $\mathbf{1 3}$ & 2016 & 7.4 & 15.9 & Wachau \\
\hline $\mathbf{8}$ & 2015 & 7.3 & 17.2 & South Styria \\
\hline $\mathbf{1 4}$ & 2017 & 7.3 & 14.7 & Leithaberg \\
\hline $\mathbf{9}$ & 2017 & 7.2 & 16.2 & Thermenregion \\
\hline $\mathbf{6}$ & 2015 & 7.2 & 15.2 & Weinviertel \\
\hline $\mathbf{1 0}$ & 2016 & 7.0 & 15.7 & South Styria \\
\hline $\mathbf{3}$ & 2016 & 6.9 & 15.3 & Thermenregion \\
\hline $\mathbf{1 5}$ & 2015 & 6.9 & 13.9 & South Styria \\
\hline $\mathbf{4}$ & 2015 & 6.6 & 14.8 & Weinviertel \\
\hline $\mathbf{5}$ & 2017 & 6.4 & 15.0 & Vienna \\
\hline
\end{tabular}

$32.456 \mathrm{~min})$, decanoic acid (129, RT: $56.551 \mathrm{~min})$, diethyl succinates (101, RT: $36.679 \mathrm{~min})$ and benzyl alcohol (108, RT: $43.932 \mathrm{~min})$.

\subsection{Statistics}

The statistical evaluation was done with SPSS 22.0 (IBM, Armonk, USA). First, the data was subjected to a descriptive analysis and checked for normal distribution. The analytical data was not normally distributed. The median value was used as the central value. The flavour analyses and basic parameters of the wines were subjected to a common principal component analysis. The scatter and charge diagram were presented in the form of a PCA biplot representation and presents the percent of the covered variance of the scattering in the two axes. The diagram was further divided into four quadrants. All analytical data was used to calculate the first and second factors. The same statistical module was used for the evaluation of the sensory evaluation by the trained panel and the consumer panel as well as the evaluation of the online questionnaire [19].

\section{Results}

\subsection{Typicity and quality of the wines}

In the course of the study, 131 Pinot blanc wines from the years 2015 to 2017 were assessed by an expert commission and a trained panel according to their typicity and overall quality. The average typicity of the 131 wines obtained from both commissions varied from 1.83 to 8.41 on a $10 \mathrm{~cm}$ scale ( 0 not typical and 10 very typical) and the overall quality from 9.73 (defective wine) to 17.44 (excellent wine). There was a strong positive correlation between the results of the two commissions $(r>0.8)$, because of they were evaluated together. Table 1 shows the typicity, quality and origin of the 15 typical wines selected for the evaluation of the wines. The alcohol content varied from 12.2 to $14.8 \%$ vol. The typicity of the wines was greater than $6.4 \mathrm{~cm}$, the quality greater than 13.9 points. 


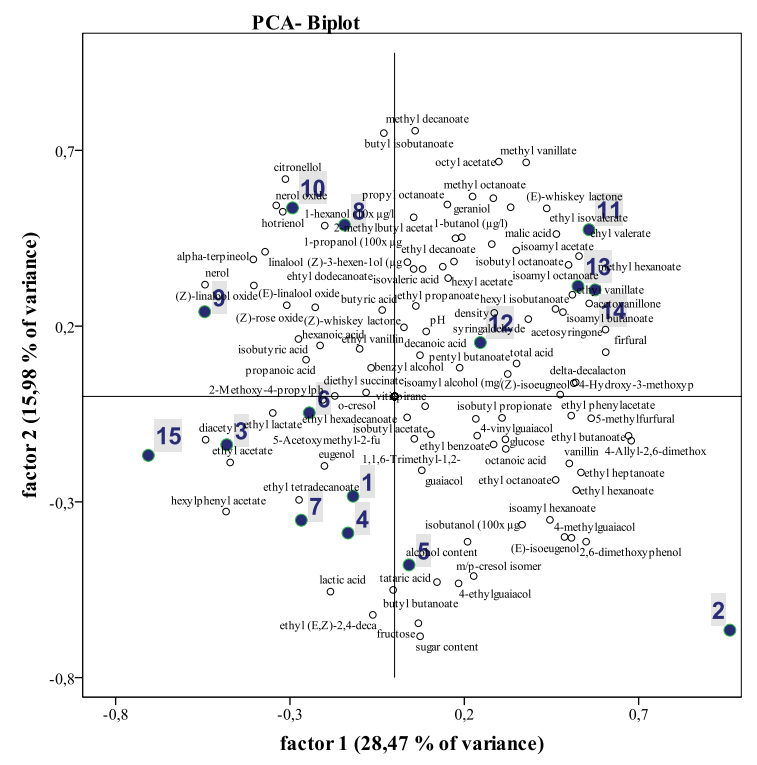

Figure 1. Principal component analysis of the results of the flavour analyses and basic parameters of the 15 evaluated wines ( $1^{\text {st }}$ quadrant top right, $2^{\text {nd }}$ quadrant top left, $3^{\text {rd }}$ quadrant bottom left, $4^{\text {th }}$ quadrant bottom right).

\subsection{Results of the aroma analyses}

102 volatile substances and some basic parameters were analysed in the 15 wines used for the evaluation (Table 2-4). A statistical evaluation of the results was achieved by means of principal component analysis (Fig. 1). It can be seen that wines 11, 13, 14 and 12 cluster together in the first quadrant. These wines showed concentrations higher than the median values for the amounts of the ethyl esters, methyl esters and isoamyl esters. Also, the values for the volatile phenols and oak substances are greater than the median concentrations, although not due to high levels of vanillin. Wine 2 differs from the other wines in the high concentrations of volatile phenols and oak substances, especially vanillin. But it also shows high concentrations of ethyl esters, methyl esters and aromatic esters. Wines 10, 8 and 9 show high levels of free monoterpenes and cluster together in the second quadrant. Unlike the cluster in Quadrant 1, the wines in Quadrant 2 are heterogeneous in terms of concentrations of esters and volatile phenols. Wine 9 has undergone a complete malolactic fermentation, which is why the ethyl lactate concentrations in this wine are very high compared to wines 10 and 8. The wines of Quadrant 3 show low ethyl ester concentrations but are heterogeneous as far as the volatile phenols and some other flavourings are concerned. Wines 3 and 15 show high ethyl acetate and diacetyl concentrations. On the basis of the lactic acid values, wines 5, 7, 4, 1, 3 and 15 show (results not presented) an incipient acid degradation or an acidification with lactic acid. Sample 5 had more residual sugar at $6 \mathrm{~g} / 1$ than the other samples $(<3 \mathrm{~g} / \mathrm{l})$.

\subsection{Sensory evaluation of the wine styles using a trained panel}

The trained panel had to group the 15 typical wines (Table 1) with regard to their perceived aroma and describe them with given terms. Figure 2 shows a main component analysis of the evaluation. Wines 1,2 and 14 are located in the first quadrant, where only wine 2 was clearly described with attributes such as oak, vanilla, wood. Wine 14 is on the border with the fourth quadrant and wine 1 on the border with the second. Wines 14, 11, 12 and 13 were often described with pineapple, apricot, very ripe apple, pear, honey and almond aroma. Wines $3,6,7,8,9,10$ and 15 are in the third quadrant or on the border to it. These wines clustered together with the terms citrus, grapefruit, meadow flower and green apple. Wines 4 and 5 are in quadrant two and generally polarised. One group of tasters described them more with green apple, wildflower, elderflower, the other group with walnut. The results were similar for wine 1. This was described as either walnut, apple compote or vanilla and wood. When comparing the results of the study of [11] with the sensory results in this study, similarities and differences are noticeable. In the old study, four styles of wine (citrus (1st style), green apple and green pear (2nd style), ripe yellow apple, quince, cooked pear, bread and honey notes (3rd style), as well as intense oak notes (4th style)) were described. It is noticeable that the differences in this study between the citrus and green apple groups could not be reproduced. Wine 2 can be numbered among the group with intensive oak notes. Wines 11, 12, 13 and 14 were described similarly to the 3rd style with some identical terms (ripe apple, pear, honey) but also others (pineapple, apricot, almond). Unlike in the study by [11], there were a number of wines that could not be clearly assigned. Among them were wines 1,4 , and 5 . Wine 1 had noticeable wood flavours, but was not clearly described with vanilla and oak. Wines 4 and 5 were described either with flower aromas or with walnut.

\subsection{Sensory evaluation of the wine styles using a consumer panel}

The consumer panel tried to divide the wines into three categories (fruity and light, fruity and complex, complex wood vanilla) along the same lines as the proposal of [20] for South African Chenin blanc. Figure 3 shows the principal component analysis of the evaluation. It turned out that wine 2 was clearly assigned to the complex wood vanilla category. Wines 1,12 and 14 were assigned to the fruity and complex group as well as occasionally to the complex wood vanilla group. Wines 4 and 13 were also numbered among the fruity and complex group but also occasionally among the fruity and light group and also occasionally to the complex wood vanilla group. Wines 7 , 9, 10 and 6 polarized the consumers. They were numbered among the fruity and light group as well as the fruity and complex group. Wine 15 , however, was clearly considered fruity and light. Wines 5, 11, 8 and 3 were increasingly assigned to the fruity and light group but occasionally also to the fruity and complex and complex wood vanilla groups. In general, it was found that the consumers showed worse reproducibility in repetitions than the trained panel.

\subsection{Results of the collection of metadata about the wines}

Of the 15 wines, 15 questions were asked via an online questionnaire. Sugar content of the musts ranged from 17 to $20{ }^{\circ} \mathrm{KMW}$. $26.7 \%$ of the wines were vinified by means of whole-cluster pressing, $20 \%$ of the wines with maceration periods shorter than $2 \mathrm{~h}, 40 \%$ of the wines 


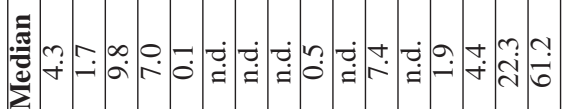

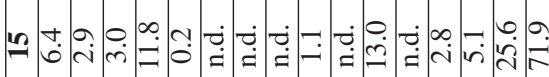

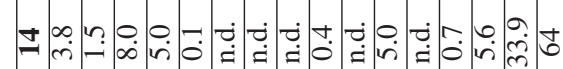

:

$\stackrel{0}{\Xi}$

in

$\stackrel{0}{ \pm}$

$\Xi$

这 言

音 贾

$\frac{n}{0}$

:

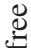

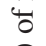

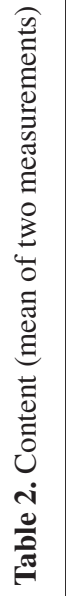

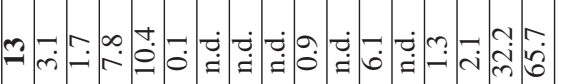

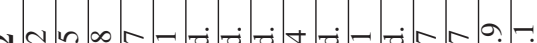

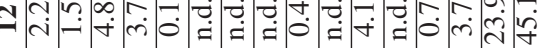

= n

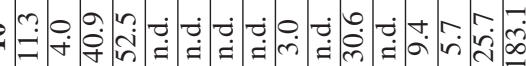

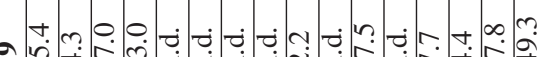

-

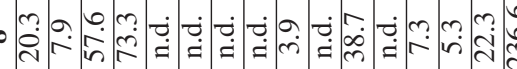

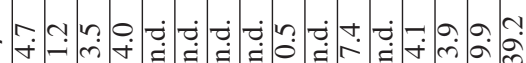

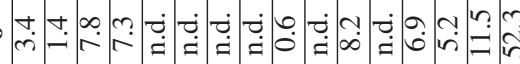

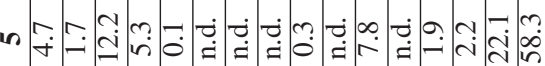

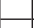

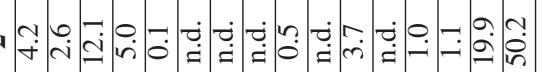

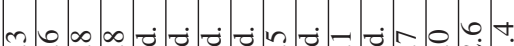

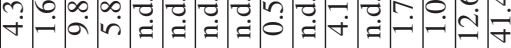

\section{$\underset{+}{+}$}

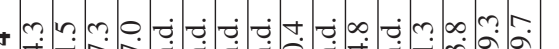

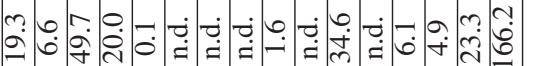

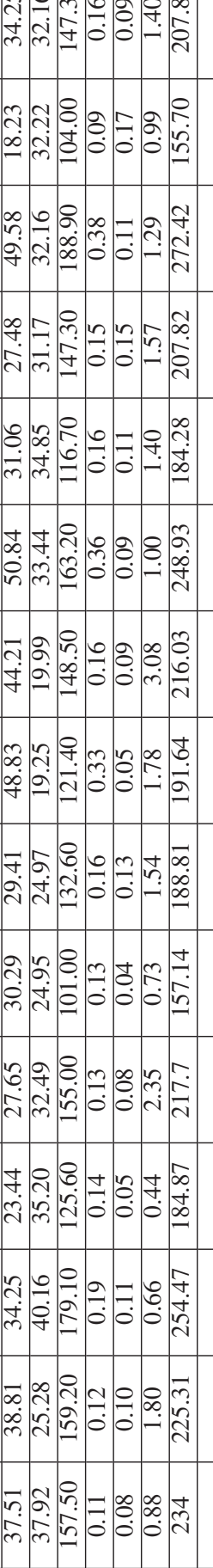

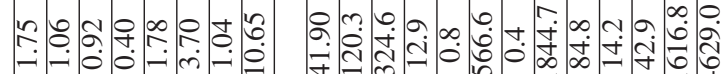

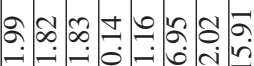

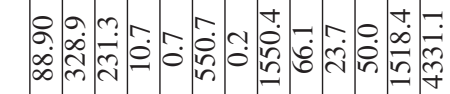

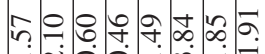

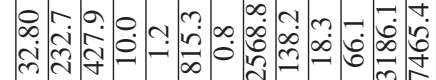

$m m m a n c o r$

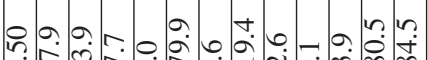

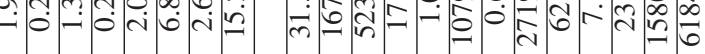

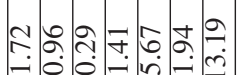

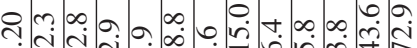

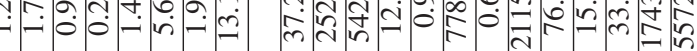

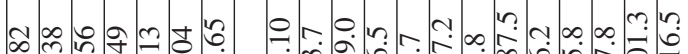

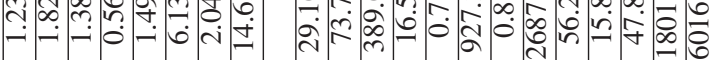

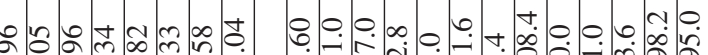

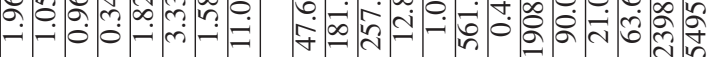

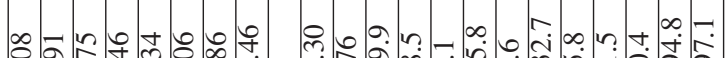

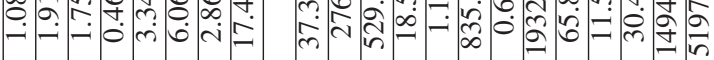

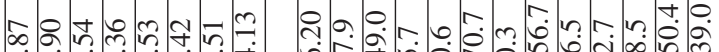

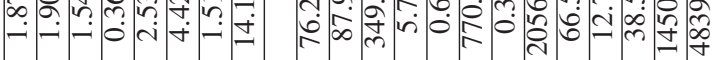

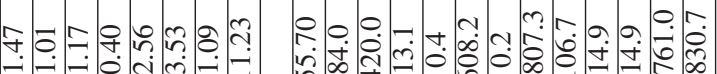

- $-\dot{0} 0$ m m

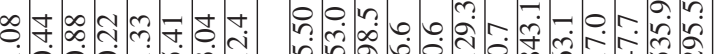

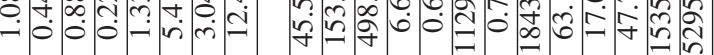

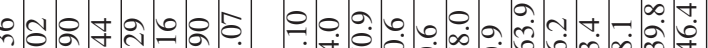

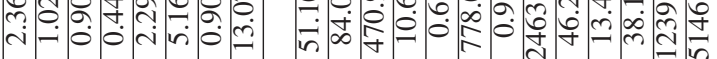

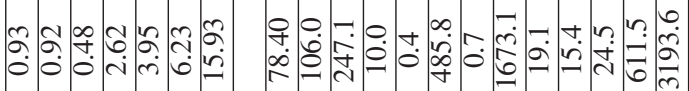

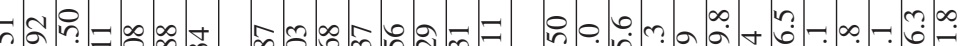

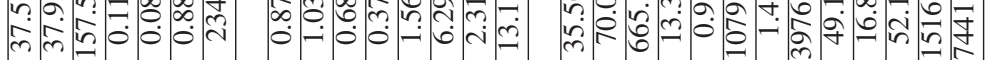

n

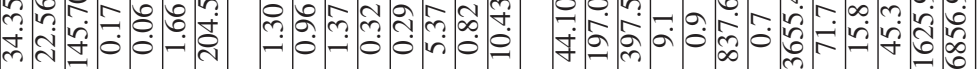

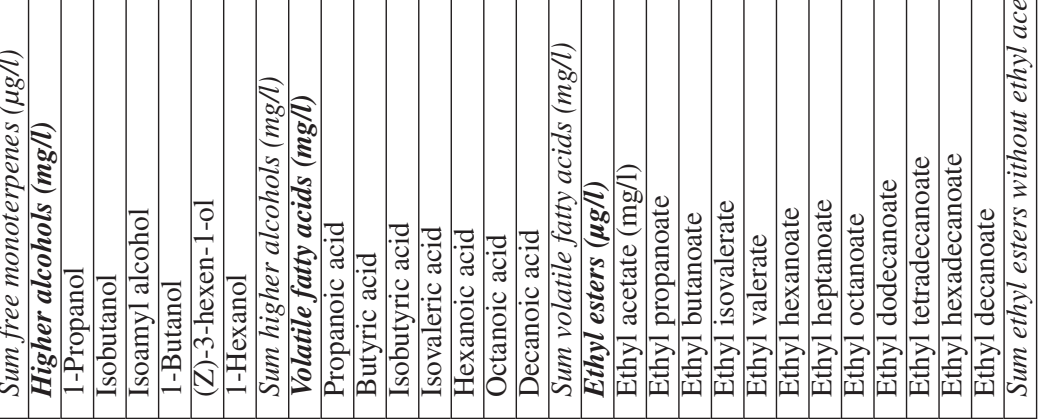




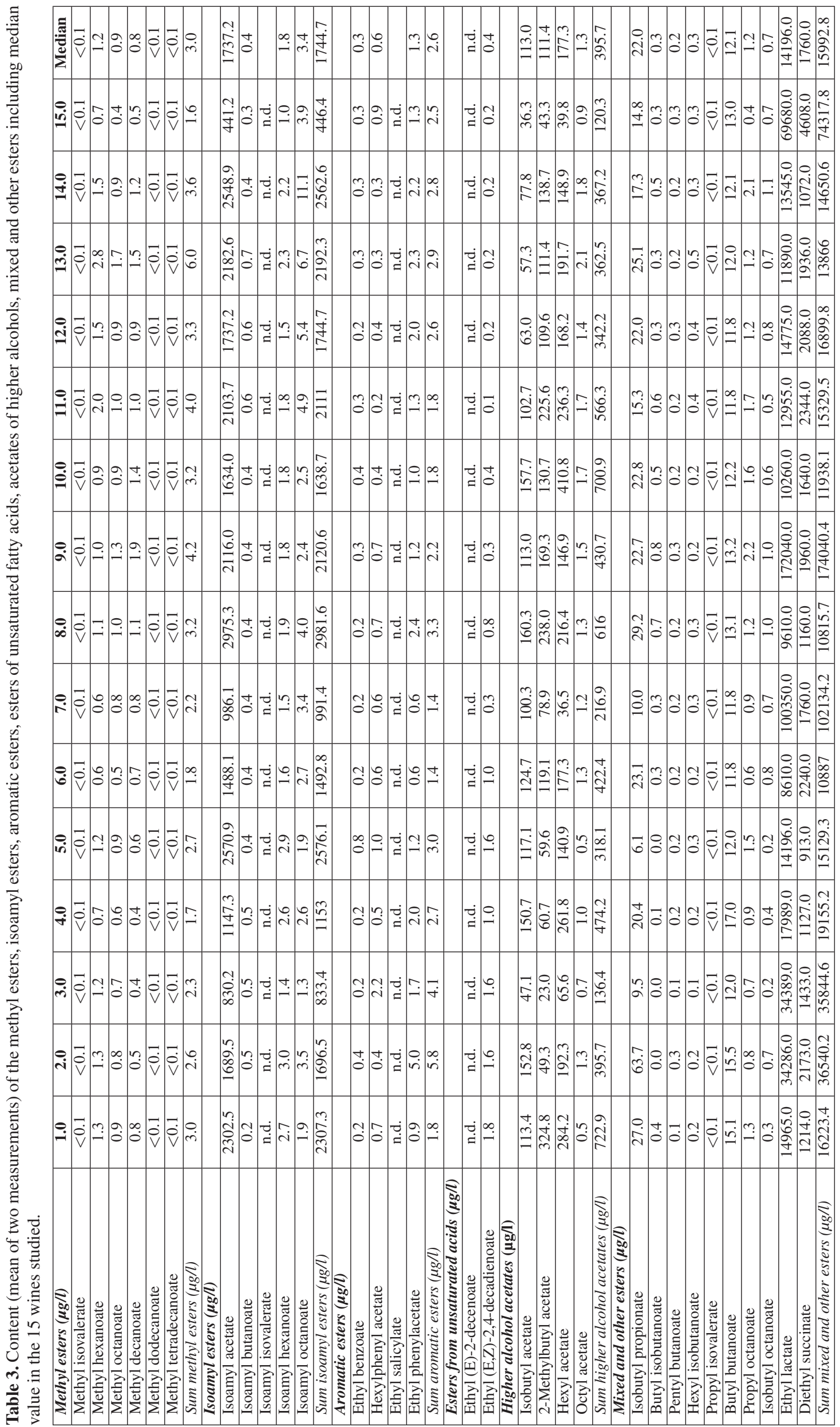




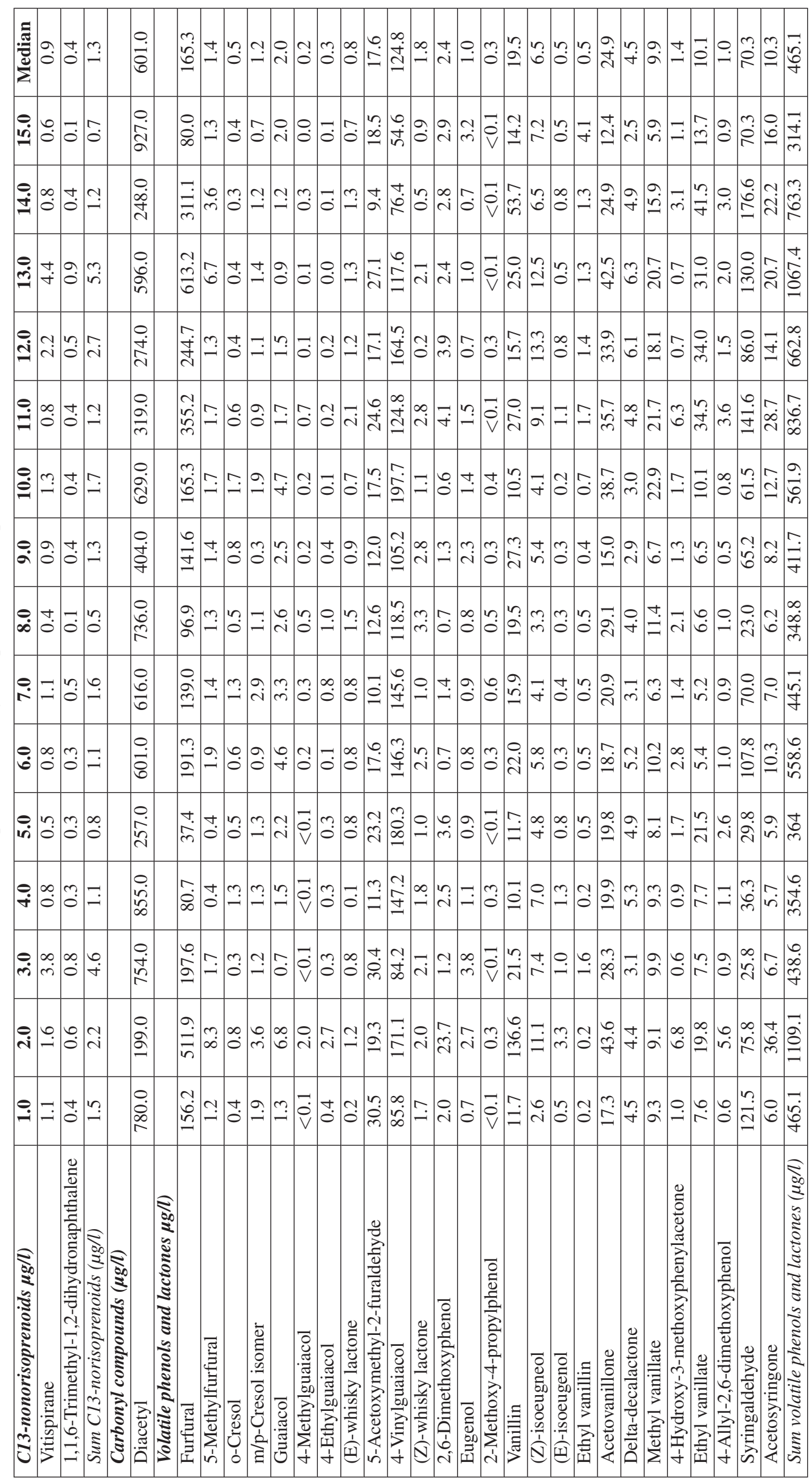




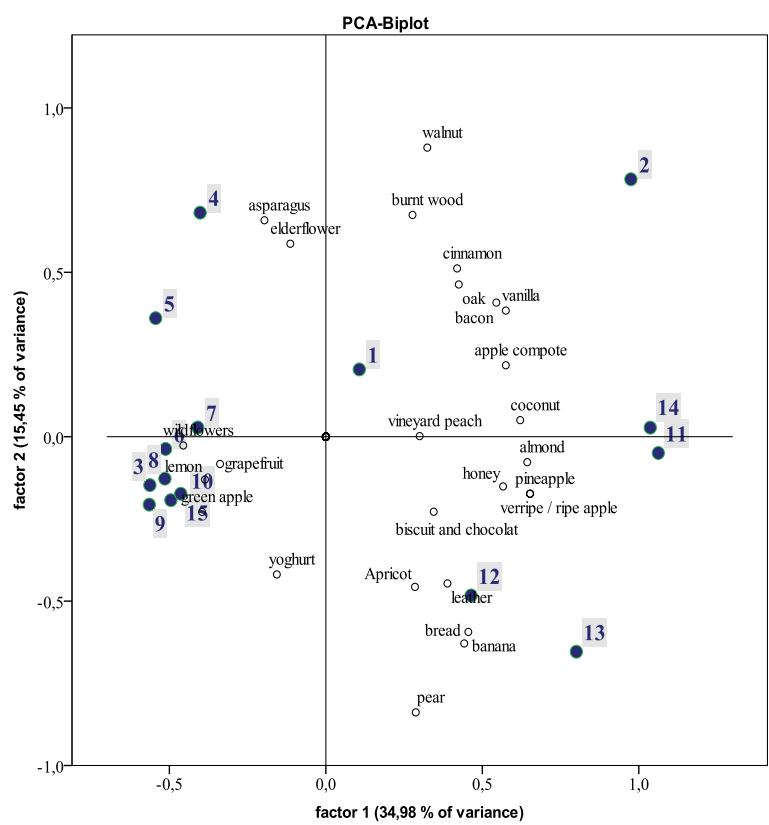

Figure 2. Principal component analysis of sensory evaluation according to aromatic wine style by means of a trained panel ( $1^{\text {st }}$ quadrant top right, $2^{\text {nd }}$ quadrant top left, $3^{\text {rd }}$ quadrant bottom left, $4^{\text {th }}$ quadrant bottom right).

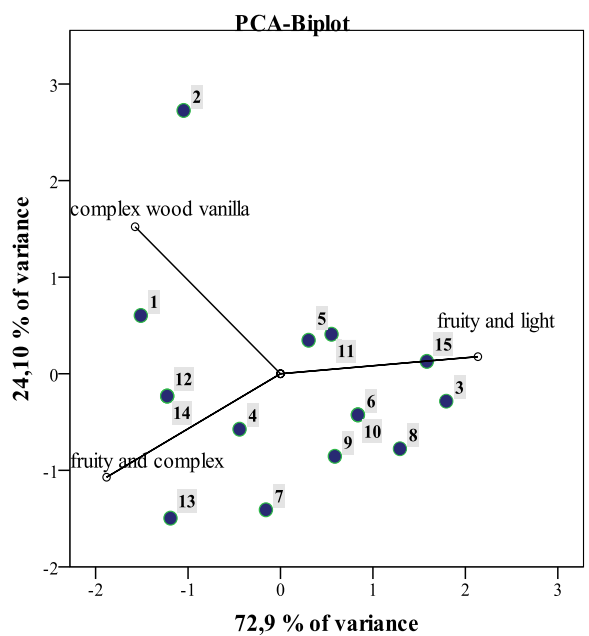

Figure 3. Principal component analysis of sensory evaluation according to aromatic wine style by means of a consumer panel.

with maceration periods between 2 and $6 \mathrm{~h}$ and $6.7 \%$ of the wines had a maceration time of more than $10 \mathrm{~h}$. Only $33 \%$ of the wines contained press fractions from pressings above 1.2 bar. $40 \%$ of the operations sedimented the musts without enzyme and $20 \%$ by flotation. $20 \%$ of the musts were not fined, however, only $6.7 \%$ of the musts were fined with combined products. $73.3 \%$ of the wines were fermented with pure cultured yeast, but only one wine was completely fermented spontaneously, the remaining wines were vinified combined. A wide variety of standard white wine yeasts (20\%), special burgundy yeasts $(46.7 \%)$ and other yeasts were used. No operation used yeasts to release monoterpenes from sugar-bound precursors (aroma yeasts). Only $20 \%$ of the wines were cleared quickly after fermentation, the remaining wines were aged on the yeast, with $46.7 \%$ of the wines even having yeast contact times longer than 6 months. $33.3 \%$ of the wines were aged only in stainless steel tanks and only one wine $100 \%$ in small oak barrels. 3 wines were not filtered sterile.

The wines in the first quadrant generally had higher sugar content, the maceration time was longer, and the yeast contact was more intense. Fermentation and storage of the wines took place in stainless steel tanks. The wines in the fourth quadrant were aged in wood. Wine 2 was also fermented in wood. The vinification of wine 15 differed from all other wines in that it fermented spontaneously, and the fermentation temperature was higher, and the wine was not sterilized. In wine 10, a combined fining was carried out in the must. Wine 9 and wine 2 had a complete acid decay. For the remaining wines, there were no distinctive abnormalities. Standard yeasts were used, the fermentation temperature was moderate, and no wood was traditionally used in the vinification.

\section{Interpretation}

In the course of this study, wines from the Pinot blanc varieties of the 2015 to 2017 vintages were tested to find out whether the wine styles proposed by [11] (citrus (1st style), green apple and green pear (2nd style), ripe yellow apple, quince, cooked pear, bread and honey notes (3rd style), as well as intense oak notes (4th style)) are sensorially and analytically reproducible. Typicity was considered by consumers, producers and wine experts. It was found that the four wine styles proposed by [11] could be partially recreated, but several gradations and transitions between the styles existed, so that an absolute distinction, with the exception of strong oak-matured wines, was even difficult with a trained panel. The results of the consumer study showed that a distinction into three groups fruity and light, fruity and complex, complex wood vanilla was more understood, but some incorrect assignments also happened here. On the other hand, the evaluation of the analytical results and the questionnaire after the oenological decisions showed that the fruity and complex group also made it possible to include some wood aromas (partial ageing in oak barrels). Thus, the three proposed wine styles, which were also understood by consumers, could be named as follows: fresh fruity (style A), complex aroma with or without moderate wood (style B) and lots of wood aroma (style C). Of course, there were fine gradations between these types of wine. In connection with the analytical data and the data of the trained panel, it can thus be stated that wine 2 belongs to the complex aroma with lots of wood group, wines 1, 4, 5, 11, 12, 13, 14 to the group complex aroma with or without moderate wood and wines $3,6,7,8,9,10,11$ and 15 to freshly fruity group. These styles (A-C) were able to withstand a discriminant analysis by substance (Fig. 4) and a sensory examination (Figs. 5 and 6).

By interviewing the winegrowers and collecting metadata for the vinification of the wines, one of them wanted to establish a direct connection between winegrowers' decisions on the aromatic profile of the wines and, finally, membership of a defined wine style.

Due to the many choices and obviously great variability in the oenological processes, this connection was only partially successful. Sample 2 was $100 \%$ fermented in new oak and stored in oak, which is why membership of style C, lots of wood aroma is clearly reproducible. Wine 15 was fermented spontaneously at 


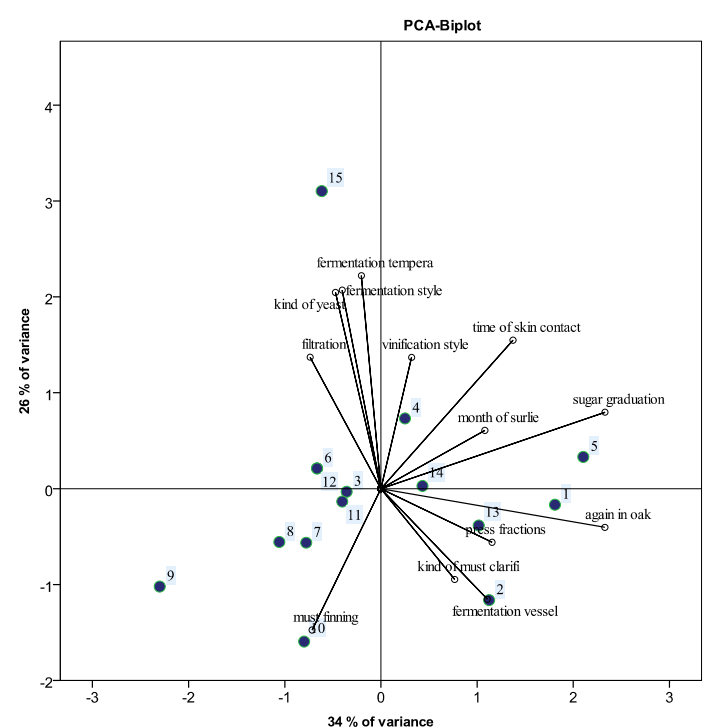

Figure 4. Main component analysis of metadata collection: (sugar graduation (numeric in month); time of skin contact (ordinal: 0 whole-bunch pressing, 1: very short time skin contact, 2: short skin contact (less than 2 hours), 3: moderate skin contact (2-5 hours), 4: long skin contact (5-10 hours), press fractions (ordinal: 1: only free run, 2: press fraction to 1.2 bar pressure, 3: press fractions more than 1.2 bar included), child of must clarification (ordinal: 0: no clarification, 1: natural sedimentation without addition of enzyme, 2: sedimentation with addition of enzyme, 3: flotation), must finning (ordinal: 0: no must finning, 1: addition of gelatine based products, 2: addition of casein based products, 3 : combination of different finning products or mixed products); fermentation style (ordinal: 1: use of $100 \%$ commercial yeast, 2: part of the 3: after starting spontaneous fermentation commercial yeasts were added, 4: spontaneous fermentation); kind of yeast (ordinal: 1: standard white wine yeast (neutral), 2: special yeasts for Pinot blanc wines, 3: aroma yeasts, 4: no yeast was added); fermentation vessel ordinal: 1: stainless steel, 2: combination of oak and stainless steel, 3: oak); fermentation temperature (1: cold fermentation (below $18^{\circ} \mathrm{C}$ ), 2: moderate temperature (between $18{ }^{\circ} \mathrm{C}$ and $21^{\circ} \mathrm{C}$ ), 3: warm fermentation (above $21^{\circ} \mathrm{C}$ )); vinification style (ordinal: 1: quick clarification after fermentation; 2: storage on the lees; 3: storage on the whole lees); month of sur lie (ordinal: 0: there is no storage on the lees, 1: short contact with lees (less than 2 months), 3 : storage on the lees for 3 months, 4 : long storage on the lees for 6 months, 5: very long storage on the lees (more than 6 months)); ageing on oak (ordinal: 0: no oak at all, 1: part of the wine in or on oak, 2: $100 \%$ of wine in or on oak); filtration (ordinal: 1: sterile filtration, 2: no sterile filtration).

higher temperatures. Due to the higher ethyl acetate concentration (Table 2), the overall fruitiness of the wine is likely to have increased. This connection is ambivalent. At low starting concentrations there is a positive correlation with the quality, if a limit is exceeded (depending on the type of wine, between $100-200 \mathrm{mg} / \mathrm{l}$ ), a noticeable acetone smell leads to negative evaluations in the case of tastings [21]. In contrast, wine 8, also with high ethyl acetate concentrations, which was also numbered among the fruity wines, but was fermented with commercial white wine yeasts. What connects the wines of the category fruity in general is short to no yeast contact times. With a few exceptions (samples 11 and 12), the complex aroma with or without moderate wood wines had yeast contact after fermentation, higher sugar content, longer maceration

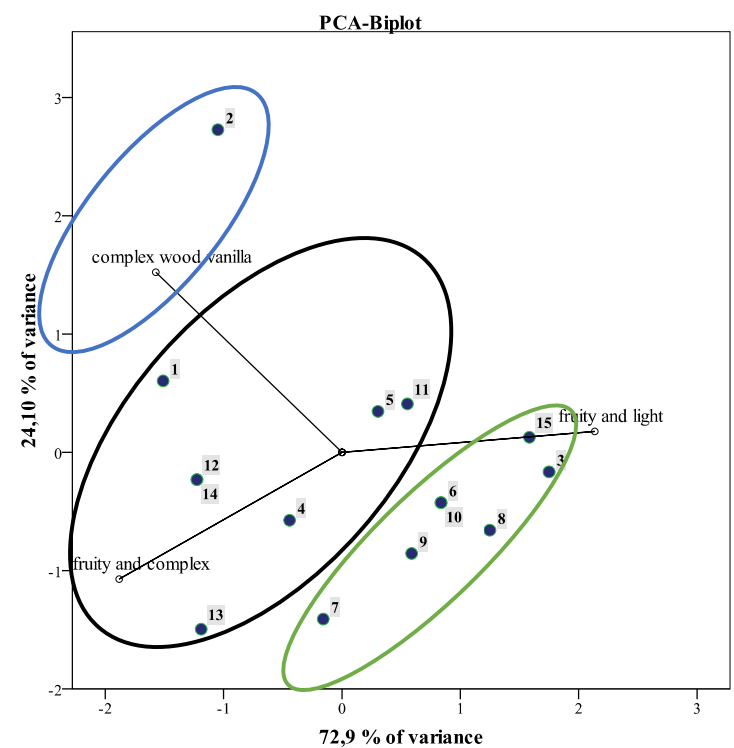

Figure 5. New wine styles (sensory data, consumer evaluation)green: fresh fruity (style A), black: comples aroma with or without moderate wood (style B) and blue: lots of wood aroma (style C), without statistical evaluation of the style boundaries.

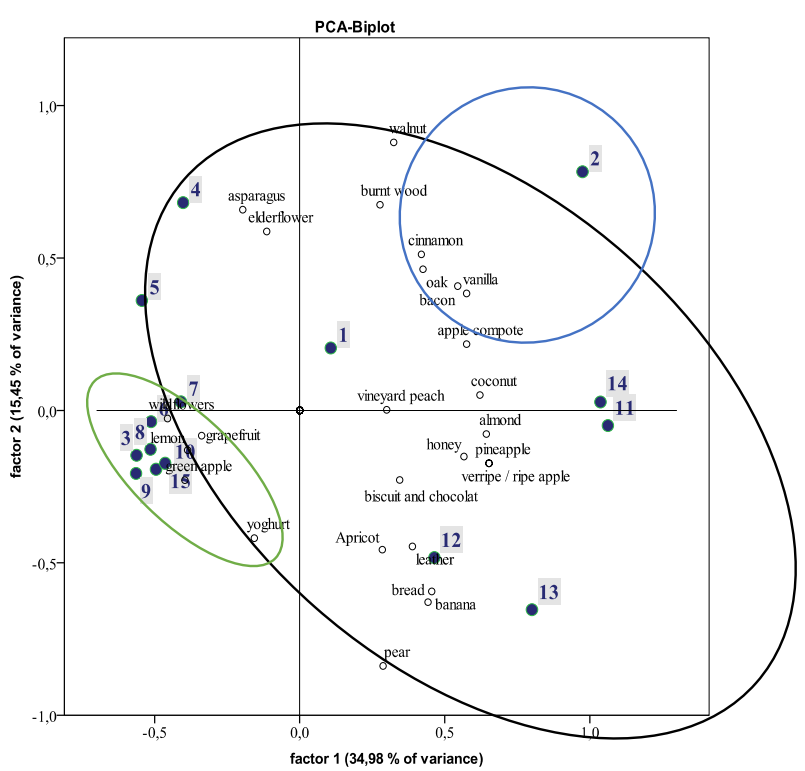

Figure 6. New wine styles (sensory data, trained panel evaluation) - green: fresh fruity (style A: green apple, grapefruit, lemon), black: complex aroma with or without moderate wood (style B: pineapple, ripe apple, apricot, pear, walnut, maybe a bit oak and vanilla) and blue: lots of wood aroma (style C: vanilla, oak, bacon, cinnamon), without statistical evaluation of the style boundaries.

times and, as already discussed, in some cases a partial storage in wooden casks.

\section{Conclusion}

The selections of 15 typical Pinot blanc wines from the years 2015 to 2017 were grouped along the same lines as their aromatic profile and sensory evaluation in three wine categories: fresh fruity (style A), complex 


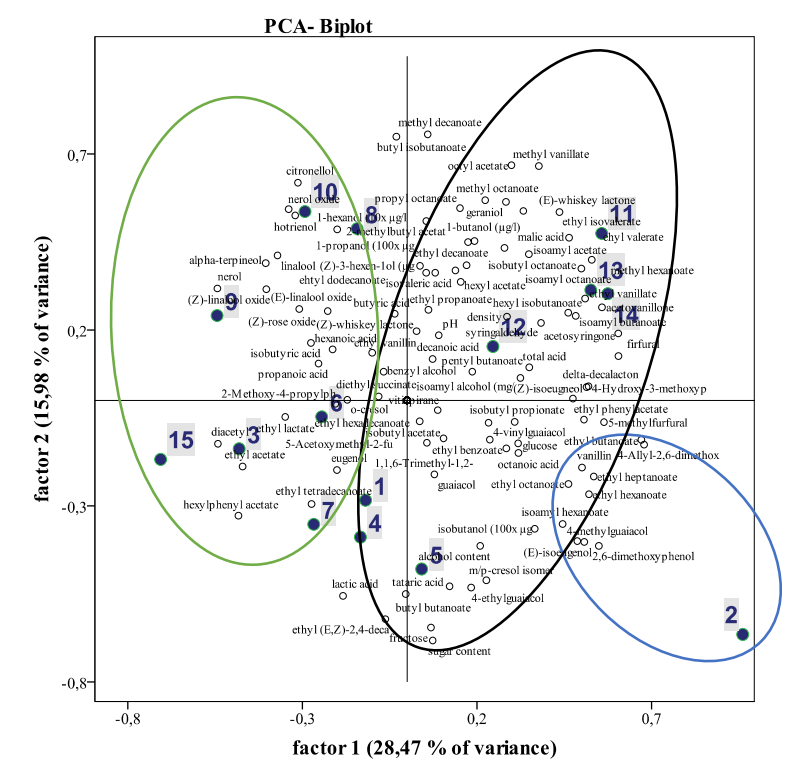

Figure 7. New wine styles (analytical data) - green: fresh fruity (style A: higher concentration of free monoterpenes, ethyl acetate), black: complex aroma with or without moderate wood (style B: higher concentration of middle and long chain ethyl esters) and blue: lots of wood aroma (style C: high concentration of vanillin), without statistical evaluation of the style boundaries.

aroma with or without moderate wood (style B) and lots of wood aroma (style C). Austria is a small but very heterogeneous wine region. The terroir concept has already been implemented differently for some grape varieties such as Grüner Veltliner, Riesling and Blaufränkisch in some areas. However, Austria's wine-growing area is probably too small and the importance of the Pinot blanc variety for the individual areas still too low to support the terroir concept for this grape variety. Which is why the proposed or another style profiling for the Pinot blanc producers could also be a first step towards better marketing and better consumer understanding. It should be noted at this point that the proposals for the style definition have been discussed with a relatively small number of samples in the course of this academic paper, so further studies and evaluations would be useful. It is necessary to further research on the question of which flavors characterize the respective wine style. An oenological guideline can help the producers to achieve the respective style. Further research work should be invested in this task too.

We would like to thank the many people who took part in the sensory evaluations on a voluntary basis. This is especially true for the 12 people of the trained tasting panel, who invested a lot of time. We would also like to thank the wine producers who made their wines available for free.

\section{References}

[1] F. Regner, C. Philipp, M. Reichl, B. Zöch, R. Hack, N. Prammer, A. Rockenbauer, Poster at XII International Conference on Grapevine Breeding and Genetics (2018)

[2] Deutsches Weininstitut, Deutscher Wein: Statistik 2017/2018 (2019)

[3] I. Maitre, R. Symoneaux, F. Jourjon, E. Mehinagic, Food Qual. Prefer. 21, 726 (2010)

[4] R. Steurer, Weißer Burgunder: Österreichischer Weinführer Band 1 Weinkultur (2002)

[5] C. Philipp, Der Winzer 9, 18 (2018)

[6] U. Perkmann, A. Ba, A. Produktion und Vermarktung von Weißburgunder - Umfrage bei den Produzenten in Deutschland, Österreich und Italien (WIFO Bericht 2016)

[7] U. Pedri, G. Pertoll, Mitt Klosterneuburg 63, 173 (2013)

[8] C. Philipp, P. Eder, W. Brandes, F. Regner, E. Patzl-Fischerleitner, E.R. Eder, BIO Web of Conferences 9, 02033 (2017)

[9] C. Philipp, P. Eder, W. Brandes, E. Patzl-Fischerleitner, R. Eder, J. Food Qual. (2018)

[10] C. Philipp, P. Eder, H. Scheiblhofer, R. Eder, R. Mitt, Klosterneuburg 68, 258 (2018)

[11] C. Philipp, S. Sari, S. Nauer, W. Brandes, E. Patzl-Fischerleitner, R. Eder. Poster at OIV Congress in Uruguay (2018)

[12] G. Giraud, Complément to the paper presented to INRA-INAO 《 terroir \& typicité » group in, 1-3 (2003)

[13] Organisation für Rebe und Wein: OIV/OENO Resolution 390/2010 (2010)

[14] H. Michlmayr, S. Nauer, W. Brandes, C. Schümann, K. Kulbe, M. Andrés, R. Eder, Food Chem 135, 80 (2012)

[15] C. Philipp, S. Nauer, S. Sari, P. Eder, E. PatzlFischerleitner, R. Eder, Mitt Klosterneuburg 69 (in print)

[16] R. Gök, Einfluss von Hefen auf die glykosidisch gebundenen Aromavorstufen und Untersuchungen zur Vermeidung der TDN-Fehlnote in Riesling (Dissertation an der TU Braunschweig 2015)

[17] W. Brandes, S. Wendelin, R. Eder, Mitt Klosterneuburg 52, 97 (2002)

[18] C. Ortega, R. Lopez, J. Cacho, V. Ferreira, J. Chrom. A 923, 205 (2001)

[19] E. J. Candès, X. Li, Y. Ma, J. Wright, JACM 58, 11 (2011)

[20] C.C. Valente, Understanding South African Chenin Blanc Wine by Using Data Mining Techniques Applied to Published Sensory Data (2016)

[21] R. Eder, W. Brandes, Weinanalyse im eigenen Betrieb: Grundparameter: Grundlagen, Methoden, Richtwerte (2003) 